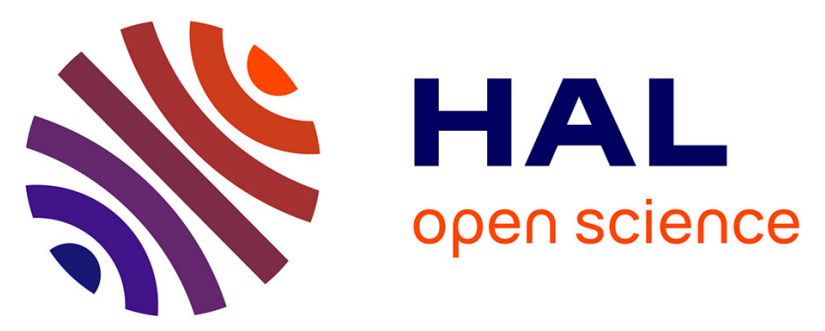

\title{
In vivo imaging of pathogen homing to the host tissues
} Joana Tavares, David Mendes Costa, Ana Rafaela Teixeira, Anabela Cordeiro-Da-Silva, Rogerio Amino

\section{To cite this version:}

Joana Tavares, David Mendes Costa, Ana Rafaela Teixeira, Anabela Cordeiro-Da-Silva, Rogerio Amino. In vivo imaging of pathogen homing to the host tissues. Methods, 2017, 127, pp.37-44. 10.1016/j.ymeth.2017.05.008 . pasteur-02425469

\section{HAL Id: pasteur-02425469}

\section{https://hal-pasteur.archives-ouvertes.fr/pasteur-02425469}

Submitted on 7 Jan 2020

HAL is a multi-disciplinary open access archive for the deposit and dissemination of scientific research documents, whether they are published or not. The documents may come from teaching and research institutions in France or abroad, or from public or private research centers.
L'archive ouverte pluridisciplinaire HAL, est destinée au dépôt et à la diffusion de documents scientifiques de niveau recherche, publiés ou non, émanant des établissements d'enseignement et de recherche français ou étrangers, des laboratoires publics ou privés.

\section{(1)(1) $\$(0)$}

Distributed under a Creative Commons Attribution - NonCommercial - ShareAlikel 4.0 


\title{
In vivo imaging of pathogen homing to the host tissues
}

\author{
JoanaTavares $^{\mathrm{ab}}$, David MendesCosta ${ }^{\mathrm{ab}}$, Ana RafaelaTeixeira ${ }^{\mathrm{ab}}$, \\ AnabelaCordeiro-da-Silva ${ }^{\text {abc }}$, RogerioAmino ${ }^{d}$ \\ a i3S - Instituto de Investigação e Inovação em Saúde, Universidade do Porto, \\ Portugal; \\ ${ }^{\mathrm{b}}$ IBMC - Instituto de Biologia Molecular e Celular, Universidade do Porto, Portugal; \\ c Faculdade de Farmácia da Universidade do Porto, Departamento de Ciências \\ Biológicas, Portugal; \\ ${ }^{\mathrm{d}}$ Unit of Malaria Infection and Immunity, Institut Pasteur, Paris, France. \\ E-mail addresses: jtavares@ibmc.up.pt (J. Tavares), rogerio.amino@pasteur.fr (R. Amino)
}

\section{Highlights}

-A novel method to visualize and quantify the homing of pathogens to tissues in the first minutes following intravascular inoculation.

- Once in the blood circulation, Plasmodium berghei sporozoites specifically home to the liver.

- Hepatotropism of Leishmania infantum amastigotes does not determine increased arrest in the liver shortly after intravascular inoculation.

Keywords: Live imaging, Arrest, Tropism, Plasmodium, Leishmania, Trypanosoma 


\begin{abstract}
Hematogenous dissemination followed by tissue tropism is a characteristic of the infectious process of many pathogens including those transmitted by blood-feeding vectors. After entering into the blood circulation, these pathogens must arrest in the target organ before they infect a specific tissue. Here, we describe a non-invasive method to visualize and quantify the homing of pathogens to the host tissues. By using in vivo bioluminescence imaging we quantify the accumulation of luciferase-expressing parasites in the host organs during the first minutes following their intravascular inoculation in mice. Using this technique we show that in the malarial infection, once in the blood circulation, most of bioluminescent Plasmodium berghei sporozoites, the parasite stage transmitted to the host skin by a mosquito bite, rapidly home to the liver where they invade and develop inside hepatocytes. This homing is specific to this developmental stage since blood stage parasites do not accumulate in the liver, as well as extracellular Trypanosoma brucei bloodstream forms and liver-infecting Leishmania infantum amastigotes. Finally, this method can be used to study the dynamics of tissue tropism of parasites, dissect the molecular and cellular basis of their increased arrest in organs and to evaluate immune interventions designed to block this targeted interaction.
\end{abstract}

\title{
INTRODUCTION
}

The use of the host circulatory system to disseminate and infect specific tissues is a recurrent characteristic observed in the lifecycle of innumerous viruses, bacteria and parasites. This tissue tropism is frequently associated with the mode of transmission of these microorganisms, as observed for pathogens that invade salivary glands of arthropod vectors and are transmitted into the host skin with the vector saliva during an infectious bite [1], [2]. Tissue tropism is also associated with the pathology caused by these microorganisms as known, for example, for the hepatitis or encephalitis-causing viruses [3]. In some cases this targeted infection can also be asymptomatic as observed for Plasmodium sporozoites, the infective malaria parasite stage inoculated in the skin during a mosquito bite. Following deposition in the skin tissue, sporozoites invade blood vessels [4], [5] and enter into the blood circulation to specifically and transiently infect the liver [6], [7], [8].

Since mammals have a closed circulatory system, the use of the blood circulation to reach specific tissues requires the arrest of the pathogen in the target organ and the ensuing crossing of the endothelial barrier, which physically separates the blood compartment from the organ parenchyma. Some organs, such as the liver, spleen and adrenal glands, are directly exposed to blood-borne pathogens due to the presence of fenestrated vessels, allowing a direct extravasation of small pathogens (e.g., fenestra diameter of hepatic sinusoids: $100 \mathrm{~nm}$ [9]), or a local open circulation. Consequently, the arrest of pathogens can be expected to occur through their binding to molecules on the surface of either tissue-specific endothelial cells or resident immune cells, or to molecules of extravascular cells exposed to the blood circulation in the case of fenestrated sinusoids and in the open splenic circulation.

The dissection of the mechanisms used by pathogens to specifically infect a tissue is hampered by the lack of an easy and quantitative method to assess this first step of arrest in the host organs following blood dissemination. The localization and quantification of pathogens in tissues usually requires the dissection of organs and the measurement of pathogen load in the excised samples by PCR, radioactive labeling, subinoculation or in vitro 
culture. On the other hand, bioluminescence imaging can reveal the distribution of living luciferase-expressing cells in a non-invasive and quantitative manner in the whole body of small hosts, such as mice. This technique, which is based on an enzymatic reaction that generates photons following the oxidation of a substrate, has been frequently applied to study Plasmodium behaviour [10] in the blood [11], [12], liver [13], [14], [15] and skin of rodents [8], [16]. The firefly luciferase has been preferentially used for in vivo studies when compared to the NanoLuc and Gaussia luciferase, which despite emitting more light in vitro, seem to be less efficient in vivo[17]. This is in part due to the higher absorption and scatter by the host tissues of the blue light emitted by their substrates [18]. Accordingly, increased in vivo sensitivity has been successfully achieved by the red-shifted variant of firefly luciferase [19], [20]. Here, using bioluminescence imaging we demonstrate the specific homing of firefly luciferase-expressing Plasmodium berghei sporozoites to the liver following the first minutes of their hematogenous dissemination.

\section{MATERIAL AND METHODS}

Mice. All experiments were carried out in accordance with the IBMC.INEB Animal Ethics Committees and the Portuguese National Authorities for Animal Health guidelines or in accordance with the Animal Care and Use Committee of Institut Pasteur both according to the statements on the directive 2010/63/EU of the European Parliament and Council. Four to six weeks old $\mathrm{C} 57 \mathrm{BL} / 6$, Swiss, NMRI or BALB/c mice were purchased from Elevage Janvier or Charles River.

Parasites. Throughout the experiments parasites used include Plasmodium berghei ANKA strain clone $676 \mathrm{cl} 1$ expressing a GFP-Luciferase fusion gene via the pbef1 a promoter [21], Trypanosoma brucei brucei Lister 427 expressing the redshifted luciferase gene (PpyRE9h) flanked by $5^{\prime}$ VSG/3'tubulin [20], [22], a cloned line of Leishmania infantum (MHOM/MA/67/ITMAP-263) expressing luciferase under the control of the intergenic region of a-tubulin [23].

To obtain $P$. berghei $(\mathrm{Pb})$ sporozoites, female Anopheles stephensi mosquitoes (SDA 500 strain) reared in the Center for the Production and Infection of Anopheles at the Pasteur Institute were infected 3-4 days after emergence and kept as previously described [24]. Sporozoites were collected from salivary glands 21-28 days after the infectious blood meal and kept on ice in PBS until inoculated into mice. Merozoites were obtained by culturing infected mouse blood in RPMI 1640 (Lonza) supplemented with 20\% heat inactivated fetal bovine serum (Biowest) and $50 \mu \mathrm{g} / \mathrm{ml}$ neomycin (Sigma) and flushed $90 \mathrm{~s}$ at 1.5-2 bar pressure with a gas mixture of $5 \% \mathrm{CO}_{2}, 5 \% \mathrm{O}_{2}$ and $90 \% \mathrm{~N}_{2}$ for $16 \mathrm{~h}$ at $37{ }^{\circ} \mathrm{C}$ and under shaking. Mature schizonts were separated using a Nycodenz (Axis Shield) gradient and merozoites were isolated by filtration of schizonts through a $1.2 \mu \mathrm{m}$ filter [25].

The bloodstream forms of $T$. b. brucei (Tb) Lister 427 were grown in HMI-9 medium (Sigma) supplemented with $10 \%$ heat inactivated fetal bovine serum (Biowest) and $100 \mathrm{IU} / \mathrm{ml}$ of penicillin/streptomycin (Lonza) at $37^{\circ} \mathrm{C}, 5 \% \mathrm{CO}_{2}$ in a humidified atmosphere [26].

L. infantum $(\mathrm{Li})$ axenic amastigotes were cultured at $37^{\circ} \mathrm{C}$, and $5 \% \mathrm{CO}_{2}$ in a cell-free medium called MAA/20 (medium for axenic amastigotes growth) as described previously [27]. Briefly, MAA/20 consisted of modified medium 199 (Invitrogen) with Hank's Balanced Salt Solution supplemented with $0.5 \%$ trypto-casein (Oxoid), $15 \mathrm{mM}$ d-glucose (Sigma), $5 \mathrm{mM}$ glutamine 
(Lonza), $4 \mathrm{mM} \mathrm{NaHCO}$, $0.023 \mathrm{mM}$ bovine hemin (Fluka) and $25 \mathrm{mM}$ HEPES (Lonza) to a final $\mathrm{pH}$ of 6.5 and supplemented with $20 \%$ heat inactivated fetal bovine serum (Biowest).

Bioluminescence imaging. Parasite loads of mice infected with luciferase-expressing parasites were assessed by bioluminescence imaging using the IVIS Lumina LT system (Perkin Elmer). Prior to infection, animals had their ventral fur shaved with an appropriate clipper. In all the models, mice were infected following the intravenous injection into the tail vein of $100 \mu$ l of parasite suspension.

For the experiments with $\mathrm{Pb}, \mathrm{C} 57 \mathrm{BL} / 6$ mice were typically infected with either $\sim 1.5 \times 10^{5}$ salivary gland sporozoites or $\sim 2$ to $6 \times 10^{7}$ blood merozoites. Infections with Tb bloodstream forms or with $\mathrm{Li}$ axenic amastigotes were performed in BALB/c mice following the inoculation of respectively $1 \times 10^{6}$ or 1 to $2 \times 10^{8}$ parasites. Immediately after parasite inoculation, mice were anesthetized with $2.5 \%$ isoflurane and four minutes after the infection, injected subcutaneously with d-luciferin $(2.4 \mathrm{mg}$, Perkin Elmer). Mice were then transferred to the stage of an intensified charge-coupled device photon-counting video camera box where anaesthesia was maintained with $2.5 \%$ isoflurane. After a three minute incubation allowing the distribution of the substrate in the body of the anesthetized animals, a five minute signal acquisition controlled by the Living Image software (Perkin Elmer) was initiated. At the end of this period animals returned to their cage and recovered from the anaesthesia. Measurement of infection by bioluminescence one day later was performed as described above.

The detection of the bioluminescence signals by the system resulted in the generation of signal maps automatically superimposed to the grey-scale photograph of the mice. The quantifications were performed using the Living Image software (Perkin Elmer). Bioluminescent signals on the regions of interest $(\mathrm{ROI})$ encompassing most of the ventral view of the animal body, thorax, liver, spleen and lower abdomen were manually defined as described below and applied to all animals. The total flux (photons/s) and average radiance (photons $/ \mathrm{s} / \mathrm{cm}^{2} /$ steradian) within these ROls was automatically calculated. ROI background signal was obtained from imaging non-infected mice that received d-luciferin as described above. The total flux or the average radiance background signal of the respective ROls were subtracted to the respective total flux or average radiance measured on infected animals. The percentage of bioluminescence in the defined ROIs (thorax, liver, spleen and lower abdomen) was calculated by dividing the total flux of the respective ROI by the total flux of the ventral animal body ROI.

Statistical analysis. All the statistical analysis and graphical representation of the data were performed using GraphPad Prism 6 software. Students $t$-test or a two-way analysis of variance (ANOVA) with Sidak's multiple comparisons test was performed and statistical significance was asserted whenever the value of $p$ was lower than 0.05 by $*(p<0.05)$, ${ }^{* *}(\mathrm{p}<0.01),{ }^{* * *}(\mathrm{p}<0.001)$ and ${ }^{* * * *}(\mathrm{p}<0.0001)$.

\section{RESULTS AND DISCUSSION}

In this study we applied 2D bioluminescence imaging to investigate the accumulation of bloodcirculating $\mathrm{Pb}$ bioluminescent sporozoites in the liver of living mice during the first minutes following their intravascular inoculation, herein defined as homing. The pattern of parasite homing was also further compared to the successful establishment of infection as measured by the distribution of the parasite bioluminescence signal one day later. 
To assess the unambiguous accumulation of sporozoites in the liver, we use different firefly luciferase-expressing blood-borne parasites with relatively similar sizes and with different specificities and capacities of invasion.

As shown in the Fig. $1 \mathrm{~A}$, once in the blood circulation, $\mathrm{Pb}$ sporozoites and merozoites invade and develop, respectively, inside hepatocytes and erythrocytes [28]; Li amastigotes are known to survive and multiply inside phagocytic cells, such as macrophages and dendritic cells of the liver, spleen and bone marrow [29], [30], and extracellular replicative Tb bloodstream forms live in the blood, lymphatic system and interstitial space of organs [31]. Therefore, the parasites used in this study include pathogens that infect the liver ( $\mathrm{Pb}$ sporozoites and $\mathrm{Li}$ amastigotes), the spleen ( $\mathrm{Li}$ amastigotes) and the blood of the host ( $\mathrm{Pb}$ merozoites and $\mathrm{Tb}$ bloodstream forms).

Taking advantage of the Living Image software that can superimpose the bioluminescence signal of parasites and the grey-scale photograph of mice, the ventrally exposed body of the host, placed in the dorsal position, was equally divided from the nostril to the perineal body in four rectangular areas, delineating the head, thorax, upper abdomen and lower abdomen (Fig. 1B). Importantly, the middle line of this zone, laying between the thorax and the upper abdominal area, coincided with the sternum, and therefore served as a robust fiducial mark. The total area of these four rectangular regions of interest (ROIs) was used to determine the total bioluminescence signal emitted by the parasites in the ventral view of the animal body (ventral ROI). Inside these rectangular ROIs and for quantification purposes, elliptical ROIs encompassing organs well known to be infected by some of the parasites listed in the Fig. $1 \mathrm{~A}$ were defined using the Living Image software and used to quantify the relative distribution of parasite load by bioluminescence at early (homing) and late (infection) time points.

In the upper abdomen, the ROI for quantifying parasite load in the liver was defined by infecting mice with luciferase-expressing $\mathrm{Pb}$ sporozoites. Two days after sporozoite inoculation in the host, when parasites reach the maximum of their intracellular development inside hepatocytes, we averaged the bioluminescence signal of three infected mice and determined the corresponding ROI of the infected liver (Fig. 1B, hepatic infection, left panel). As expected, the liver was the only visceral organ to emit photons and the hepatic ROI was placed just bellow the sternum matching the model illustrated in the IVIS mouse atlas model (Fig. 1B, right panel). The position of the liver using bioluminescence was confirmed using luciferase-expressing Li amastigotes. Accordingly, the hepatic ROI obtained using amastigote infection corresponded to the bioluminescence signal of sporozoite infection (Fig. 1B, left and middle panel). In addition, amastigotes also infected a region adjacent to and distinct from the hepatic ROI, which according to its anatomical position and the tissue tropism of amastigotes should correspond to the ventral extremity of the spleen (Fig. 1B, splenic infection, middle panel). To quantify the relative load of parasites in the thorax, which contains the lungs, thymus and heart, and in the lower abdomen, which contains the intestine and bladder among other organs, the elliptical area of the hepatic ROI defined using the $\mathrm{Pb}$ sporozoite infection was transposed to the thorax and lower abdomen rectangular areas, and was defined as thoracic and lower abdominal ROls, respectively (Fig. 1B, right panel).

The homing and infectivity of the different parasites were determined by measuring the intensity of the parasite bioluminescence throughout the anatomical regions defined above (thoracic, hepatic, splenic and lower abdominal ROIs) relative to that of the ventral view of the animal body (ventral ROI). For that, the total flux (photons/s) of the respective ROI was divided by the total flux of the ventral ROI, previously subtracted by the background values calculated from non-infected animals. In addition, the parasite development in the tissues was 
evaluated by comparing the average radiance (photons $/ \mathrm{s} / \mathrm{cm}^{2} /$ steradian) of ROls at early (homing) and late (infection) time points.

Once in the blood circulation, Plasmodium sporozoites are known to transform and multiply into merozoites, the red blood cells infective forms, exclusively inside hepatocytes [6], [7], [8]. Sporozoites can be detected in the liver a few minutes after intravascular inoculation [16], [32]. After two hours, most of injected sporozoites accumulate in the liver [33]. Therefore, prior to invading hepatocytes, sporozoites passively transported in the blood must arrest in the liver sinusoids. This arrest has been proposed to be due to both a slower blood circulation speed in the sinusoids and the interaction of the most abundant sporozoite surface protein, the circumsporozoite protein (CSP) with the highly sulphated proteoglycans that protrude through the fenestra of endothelial cells [28], [34]. Noteworthy, the current model explaining this crucial step is based on indirect experiments interpreting the binding of recombinant proteins to hepatocytes or the outcome of a liver infection by sporozoites. When and how sporozoites arrest in the liver is still an unsettled issue.

To evaluate whether Plasmodium sporozoites specifically home to the liver in the first minutes following their intravascular inoculation in C57BL6 mice, the distribution and relative intensity of the bioluminescence signal emitted by luciferase-expressing sporozoites was calculated in the previously defined ROls and compared to that obtained after injection of luciferaseexpressing blood merozoites. Using this method, $\sim 70 \%$ of the total bioluminescence signal detected $7 \mathrm{~min}$ after the intravenous injection of sporozoites was found in the liver ROI, contrasting with only $\sim 20 \%$ after injection of merozoites (Fig. 2A and B). While sporozoite bioluminescence is clearly concentrated in the liver, the bioluminescence of merozoites is seen all over the body suggesting parasites are in circulation. Indeed, free merozoites recognize, attach, and invade red blood cells and this process occurs rapidly, in the order of minutes, as the antigens present on the parasite surface are susceptible to immune attack [35]. Inside red blood cells, they develop through the ring, trophozoite, and schizont stages, replicating to produce between 16 and 32 daughter merozoites. After egressing from the infected cell and invading another red blood cell, these merozoites initiate a new cycle of multiplication. This cyclic process is responsible for the clinical manifestations of malaria and lasts nearly $24 \mathrm{~h}$ in rodents [35]. Therefore, one day after merozoite injection, the bioluminescence signal remained distributed all over the animal body while concentrated in the liver of mice infected with sporozoites. Indeed, in the latter $\sim 90 \%$ of the total bioluminescent signal was detected in the liver versus $20 \%$ in mice inoculated with merozoites (Fig. 2C and D). Notably, the pattern of parasite distribution in the ROls, concentrated in the liver after sporozoite injection and disseminated through the body after merozoite injection, did not change substantially from the homing and infection time points. In the first case, this indicates that sporozoites rapidly accumulate in the liver to establish the infection of hepatocytes. In the second, this similarity suggests that merozoites and infected red blood cells are principally circulating in the vasculature. The exponential multiplication of parasites in the liver (Fig. 2E) or in the blood (Fig. 2F) was assessed by quantifying the average radiance of the bioluminescence signal respectively, in the hepatic and ventral ROls.

In the range of 75,000-300,000 injected sporozoites, a linear relationship is observed between the number of injected parasites and the average bioluminescence quantified in the hepatic $\mathrm{ROI}$ in the first minutes post-inoculation (Fig. $2 \mathrm{G}, \mathrm{R}^{2}=0.99$ ). Therefore, this method can be used to quantify not only changes in the parasite relative distribution (homing pattern) but also in the sporozoite load, early during the hepatic infection. 
To confirm the specificity of sporozoite homing to the liver, another blood circulating bioluminescent parasite, the extracellular replicative monomorphic $\mathrm{Tb}$ was intravenously injected into BALB/C mice. The relative distribution of the bioluminescence signal of $\mathrm{Tb}$ bloodstream forms was quantified using the pre-defined ROls (Fig. 3) and compared to that obtained using Plasmodium parasites (Fig. 2). Immediately after intravascular inoculation, the bioluminescence signal was detected all over the body as observed following $\mathrm{Pb}$ merozoite injection. Similar percentages of bioluminescence in the hepatic $(\sim 20 \%)$ and in the other ROIs strongly indicate that both $\mathrm{Pb}$ merozoites and $\mathrm{Tb}$ bloodstream forms are circulating with the same pattern in the blood, presumably without any detectable specific arrest in the organs (Fig. 3A and B). Consequently, the values obtained in the ROIs should correspond approximately to the percentual blood volume of these regions. Indeed, the value of $20 \%$ of total bioluminescence in the liver is in the range (14-30\%) of the total blood percentage found in the liver [36], [37]. The distribution of Tb bloodstream forms in the ROls did not also change substantially at the homing and infection time points, except for the splenic ROI. Owing to parasite multiplication the average radiance in the thorax, liver and lower abdomen increased $\sim 15$-fold from the first minutes after infection to day 1 , contrasting with the 90 -fold observed in the splenic ROI (Fig. 3C).

To determine if the capacity to infect the liver is associated with the homing of parasites to this organ as seen for sporozoites, we assess the distribution pattern of bioluminescent $\mathrm{Li}$ amastigotes known to infect macrophages including those of the liver, as depicted in the Fig. 1B. Shortly after intravenous injection of amastigotes into BALB/c mice, bioluminescence is mostly observed in the thorax, presumably in the right and left lungs given the anatomical position and shape of the signal, as well as, in the spleen and in the liver (Fig. 4A). The spleen and the liver are known to harbour resident macrophages, which can contact the blood and clear particulate material from the circulation [38]. Interestingly, the bioluminescence signal of amastigotes in the liver, $\sim 20 \%$ of the total signal, did not statistically differ from the percentage observed using injection of blood-circulating $\mathrm{Tb}$ bloodstream forms and $\mathrm{Pb}$ merozoites (Fig. $5 \mathrm{~A}$ ), in clear contrast with the $70 \%$ of $\mathrm{Pb}$ sporozoites that accumulated in the liver. These results show that despite infecting the liver, $\mathrm{Li}$ amastigotes do not significantly accumulate in this organ shortly after intravascular inoculation. On the other hand, the accumulation of amastigotes in the spleen was significantly higher than those of $\mathrm{Pb}$ merozoites and Tb bloodstream forms, indicating a preference of $\mathrm{Li}$ amastigotes to accumulate in this organ. Regarding the distribution of amastigotes in the thoracic region, despite the distinctive pulmonary pattern, the percentage of bioluminescence was not statistically different from $\mathrm{Tb}$ injection but differed from $\mathrm{Pb}$ merozoites, complicating the interpretation of the data (Fig. 5A). Importantly, the percentage of the total bioluminescence detected in the thorax decreased from $\sim 40$ to $5 \%$ when comparing the first minutes after $\mathrm{Li}$ amastigotes inoculation to day 1 (Fig. 4B), while it increased in the liver and spleen from $\sim 20$ to $>40 \%$ and from $\sim 20$ to $35 \%$, respectively (Fig. 5). Analysis of the average radiance shows a significant reduction in the signal detected in the thorax at day 1 comparing to $7 \mathrm{~min}$ post-inoculation indicating that the parasites initially observed in the thorax were cleared in the lungs in the case of a possible arrest in this region or they were simply removed from the circulation by phagocytes of the liver, spleen, bone marrow or blood (Fig. 4C).

The liver can rapidly clear microorganisms from the blood circulation [39] through the scavenging activity of Kupffer [40], [41] and endothelial cells [42]. This clearance can be extremely fast, mediated by the direct recognition of pathogens [41], or relatively slower, mediated by the recognition of host molecules bound to the opsonized pathogens [43]. However, some pathogens, such as Li amastigotes, can survive to this clearing activity and 
exploit this scavenging function to arrest and specifically infect the liver. Plasmodium sporozoites are known to be captured by KCs in the lumen of liver sinusoids [44], presumably by the interaction of CD68 with the parasite GAPDH [45], [46]. After a transitory interaction with $\mathrm{KCs}$, most sporozoites escape from a phagocytic death by traversing these cells and either return to the blood circulation or invade the hepatic parenchyma [44]. However, KCs do not seem to be directly involved in the homing of sporozoites to the liver, since their depletion by liposome-encapsulated clodronate, rather increases the hepatic infection [47], [48]. In vivo imaging indeed indicates that sporozoites bind to endothelial cells prior to the crossing of the sinusoidal barrier after interacting, or not, with KCs [44], [49]. The lack of the intercellular adhesion molecule (ICAM) 1 and 2, complement factors C3 and C4 [50], LDL receptor related protein [51], CD36 [52] or macrophage scavenger receptors (SR) $\mathrm{Al}$ and All [53] does not change sporozoite infectivity in mice, indicating that these molecules are also unlike to play a role in the sporozoite homing. On the other hand, the sulfated polysaccharides, dextran sulfate and fucoidan, can inhibit sporozoite infectivity in vivo[54], while the role of SR-BI still remains controversial [55], [56], [57]. In all these cases, sporozoite infectivity is assessed by the measurement of parasite load in the liver two days post-infection, rendering impossible the discrimination of an effect of these molecules on sporozoite homing from an inhibitory effect on the invasion and/or development inside hepatocytes. This novel homing method can therefore be used to reassess the impact of these molecules and cells in the specific arrest of sporozoites in the liver. For example, combining this method with the use of mice lacking CD68 [58], stellate cells [59] or KCs [48], [49], or alternatively, with the targeting of putative arrest/invasion receptors, such as CD81 [60], SR-BI [55], [56], [57] and EphA2 [61], will allow the elucidation of the role played by these factors in the sporozoite homing. Complementary to this approach, mutant sporozoites lacking adhesion molecules or neutralizing antibodies can be used to determine the impact of parasite proteins on the specific accumulation of sporozoites in the liver. Finally, this method can be adapted for the quantification of the homing of bioluminescent humaninfecting sporozoites to the liver of humanized mice harboring human hepatocytes [15], [57].

\section{CONCLUSION}

A complete picture of increased arrest and subsequent development of parasites in organs, defined here respectively, as homing and infection is shown in the Fig. 5. The increased arrest leading to parasite accumulation in organs was defined by statistical comparison with the distribution of blood-circulating parasites, $\mathrm{Pb}$ merozoites and $\mathrm{Tb}$ bloodstream forms. Based on this parameter, we conclude that $\mathrm{Pb}$ sporozoites specifically home to the liver in contrast to $\mathrm{Pb}$ merozoites, Tb bloodstream forms and even liver-infecting Li amastigotes. Interestingly, using this methodology, we observe the splenic and hepatic infection of amastigotes, but only the parasite accumulation in the spleen statistically differs from the distribution of both bloodcirculating control parasites. These results allow us to clearly discriminate at an early time point of analysis the increased arrest (homing step) from the regular arrest of parasite in organs, both leading to a specific tissue infection (tissue tropism).

The combination of this non-invasive and quantitative imaging method with genetically modified pathogens and transgenic mouse strains lacking surface molecules on putative target cells will be key to dissect the molecular mechanisms involved in the homing of microorganisms to tissues following hematogenous dissemination. Finally the use of hosts immunized against pathogen molecules involved in this arrest step certainly will assist in the design of better strategies to prevent infection. 


\section{FUNDING}

This work was supported by funds from the Fundação para a Ciência e Tecnologia (FCT)/Ministério da Educação e Ciência (MEC) co-funded by FEDER (EXPL/JTAVARESIF/00881/2012/CP0158/CT0005, EXPL/IMI-MIC/1331/2013) under the Partnership agreement PT2020, through the Research Unit No.4293, the Institut Paris - Paris, the French National Research Agency (Grant No. ANR-10-JCJC-1302-PlasmoPEP), the French Government's Investissement d'Avenir program, Laboratoire d'Excellence "Integrative Biology of Emerging Infectious Diseases" (Grant No. ANR-10-LABX-62-IBEID). JT is an Investigator FCT funded by National funds through FCT and co-funded through European Social Fund within the Human Potential Operating Programme. DC is funded by FCT (SFRH/BD/123734/2016).

\section{ACKNOWLEDGEMENTS}

We would like to acknowledge the team of the Center of Production and Infection of Anopheles (CEPIA), Institut Pasteur, in particular Marek Szatanik, Catherine Thouvenot and Sylvain Golba for providing the Anopheles stephensi female mosquitos; the team of the Platform of Dynamic Imaging, Institut Pasteur, in particular Spencer Shorte and Marie-Anne Nicola for the help with bioluminescence imaging; Martin Taylor from the London School of Hygiene and Tropical Medicine for kindly providing the construct used to generate the T. $b$. brucei Lister 427 strain expressing the red-shifted luciferase.

\section{REFERENCES}

[1]R. Ross The role of the mosquito in the evolution of the malaria parasite Lancet, 2 (1898), p. 489.

[2] M.J. Conway, T.M. Colpitts, E. Fikrig Role of the vector in arbovirus transmission Annu. Rev. Virol., 1 (2014), pp. 71-88.

[3] J. Schneider-Schaulies Cellular receptors for viruses: links to tropism and pathogenesis J. Gen. Virol., 81 (2000), pp. 1413-1429.

[4] J.P. Vanderberg, U. Frevert Intravital microscopy demonstrating antibody-mediated immobilisation of sporozoites injected into skin by mosquitoes Int. J. Parasitol., 34 (2004), pp. 991-996.

[5] R. Amino, S. Thiberge, B. Martin, S. Celli, S. Shorte, F. Frischknecht, R. Ménard Quantitative imaging of Plasmodium transmission from mosquito to mammal Nat. Med., 12 (2006), pp. 220-224.

[6] H.E. Shortt, P.C. Garnham Pre-erythrocytic stage in mammalian malaria parasites Nature, 161 (1948), p. 126.

[7] J.P. Vanderberg Plasmodium berghei exoerythrocytic forms develop only in the liver Trans. R. Soc. Trop. Med. Hyg., 75 (1981), pp. 904-905.

INSTITUTO DE INVESTIIGAÇÃO E INOVACCÃO EM SAÚDE UNIVERSIDADE DO PORTO

Rua Alfredo Allen, 208 4200-135 Porto Portugal +351220408800 publications, please visit http://repositorio-aberto.up.pt/ 
[8] P. Gueirard, J. Tavares, S. Thiberge, F. Bernex, T. Ishino, G. Milon, B. Franke-Fayard, C.J. Janse, R. Ménard, R. Amino Development of the malaria parasite in the skin of the mammalian host Proc. Natl. Acad. Sci. U S A, 107 (2010), pp. 18640-18645.

[9] E. Wisse, F. Jacobs, B. Topal, P. Frederik, B. De Geest The size of endothelial fenestrae in human liver sinusoids: implications for hepatocyte-directed gene transfer Gene Ther., 15 (2008), pp. 1193-1199.

[10] M. De Niz, R.R. Stanway, R. Wacker, D. Keller, V.T. Heussler An ultrasensitive NanoLuc-based luminescence system for monitoring Plasmodium berghei throughout its life cycle Malar J., 15 (2016), p. 232.

[11] B. Franke-Fayard, C.J. Janse, M. Cunha-Rodrigues, J. Ramesar, P. Büscher, I. Que, C. Löwik, P.J. Voshol, M.A. den Boer, S.G. van Duinen, M. Febbraio, M.M. Mota, A.P. Waters Murine malaria parasite sequestration: CD36 is the major receptor, but cerebral pathology is unlinked to sequestration Proc. Natl. Acad. Sci. U. S. A., 102 (2005), pp. 11468-11473.

[12] B. Franke-Fayard, A.P. Waters, C.J. Janse Real-time in vivo imaging of transgenic bioluminescent blood stages of rodent malaria parasites in mice Nat. Protoc., 1 (2006), pp. 476-485.

[13] A. Mwakingwe, L.M. Ting, S. Hochman, J. Chen, P. Sinnis, K. Kim Noninvasive realtime monitoring of liver-stage development of bioluminescent Plasmodium parasites $\mathrm{J}$. Infect. Dis., 200 (2009), pp. 1470-1478.

[14] I.H. Ploemen, M. Prudêncio, B.G. Douradinha, J. Ramesar, J. Fonager, G.J. van Gemert, A.J. Luty, C.C. Hermsen, R.W. Sauerwein, F.G. Baptista, M.M. Mota, A.P. Waters, I. Que, C.W. Lowik, S.M. Khan, C.J. Janse, B.M. Franke-Fayard Visualisation and quantitative analysis of the rodent malaria liver stage by real time imaging PLoS ONE, 18 (2009), p. e7881.

[15] A.S. Yang, M.T. O'Neill, C. Jennison, S. Lopaticki, C.C. Allison, J.S. Armistead, S.M. Erickson, K.L. Rogers, A.M. Ellisdon, J.C. Whisstock, R.E. Tweedell, R.R. Dinglasan, D.N. Douglas, N.M. Kneteman, J.A. Boddey Cell traversal activity is important for Plasmodium falciparum liver infection in humanized mice Cell Rep., 18 (2017), pp. 3105-3116.

[16] H. Matsuoka, H. Tomita, R. Hattori, M. Arai, M. Hirai Visualization of Malaria parasites in the skin using the luciferase transgenic parasite, Plasmodium berghei Trop. Med. Health., 43 (2015), pp. 53-61.

[17] A.C. Stacer, S. Nyati, P. Moudgil, R. lyengar, K.E. Luker, A. Rehemtulla, G.D. Luker NanoLuc reporter for dual luciferase imaging in living animals Mol. Imaging., 12 (2013), pp. 1-13.

[18] S.L. Jacques Optical properties of biological tissues: a review Phys. Med. Biol., 58 (2013), pp. R37-R61.

[19] M.L. Foucault, L. Thomas, S. Goussard, B.R. Branchini, C. Grillot-Courvalin In vivo bioluminescence imaging for the study of intestinal colonization by Escherichia coli in mice Appl. Environ. Microbiol., 76 (2010), pp. 264-274. 
[20] A.P. McLatchie, H. Burrell-Saward, E. Myburgh, M.D. Lewis, T.H. Ward, J.C. Mottram, S.L. Croft, J.M. Kelly, M.C. Taylor Highly sensitive in vivo imaging of Trypanosoma brucei expressing “red-shifted” luciferase PLoS Negl. Trop. Dis., 7 (2013), p. e2571.

[21] B. Franke-Fayard, D. Djokovic, M.W. Dooren, J. Ramesar, A.P. Waters, M.O. Falade, M. Kranendonk, A. Martinelli, P. Cravo, C.J. Janse Simple and sensitive antimalarial drug screening in vitro and in vivo using transgenic luciferase expressing Plasmodium berghei parasites Int. J. Parasitol., 38 (2008), pp. 1651-1662.

[22] N.A. Graça, L. Gaspar, D.M. Costa, I. Loureiro, P.K. Thoo-Lin, I. Ramos, M. Roura, A. Pruvost, I.K. Pemberton, H. Loukil, J. MacDougall, J. Tavares, A. Cordeiro-da-Silva Activity of bisnaphthalimidopropyl derivatives against Trypanosoma brucei Antimicrob. Agents Chemother., 60 (2016), pp. 2532-2536.

[23] D. Sereno, G. Roy, J.L. Lemesre, B. Papadopoulou, M. Ouellette DNA transformation of Leishmania infantum axenic amastigotes and their use in drug screening Antimicrob. Agents Chemother., 45 (2001), pp. 1168-1173.

[24] R. Amino, S. Thiberge, S. Blazquez, P. Baldacci, O. Renaud, S. Shorte, R. Ménard Imaging malaria sporozoites in the dermis of the mammalian host Nat. Protoc., 2 (2007), pp. 1705-1712.

[25] C.J. Janse, J. Ramesar, A.P. Waters High-efficiency transfection and drug selection of genetically transformed blood stages of the rodent malaria parasite Plasmodium berghei Nat. Protoc., 1 (2006), pp. 346-356.

[26] I. Loureiro, J. Faria, C. Clayton, S.M. Ribeiro, N. Roy, N. Santarém, J. Tavares, A. Cordeiro-da-Silva Knockdown of asparagine synthetase A renders Trypanosoma brucei auxotrophic to asparagine PLoS Negl. Trop. Dis., 7 (2013), p. e2578.

[27] J. Tavares, A. Ouaissi, P. Kong, I. Thoo Lin, S. Loureiro, S. Kaur, N. Roy, A. Cordeiro-daSilva Bisnaphthalimidopropyl derivatives as inhibitors of Leishmania SIR2 related protein 1 ChemMedChem, 5 (2010), pp. 140-147.

[28] R. Ménard, J. Tavares, I. Cockburn, M. Markus, F. Zavala, R. Amino Looking under the skin: the first steps in malarial infection and immunity Nat. Rev. Microbiol., 11 (2013), pp. 701-712.

[29] P. Kaye, P. Scott Leishmaniasis: complexity at the host-pathogen interface Nat. Rev. Microbiol., 9 (2011), pp. 604-615.

[30] L.I. McCall, W.W. Zhang, G. Matlashewski Determinants of the development of Visceral Leishmaniasis disease PLoS Pathog., 9 (2013), p. e1003053.

[31] P.G. Kennedy Clinical features, diagnosis, and treatment of human African trypanosomiasis (sleeping sickness) Lancet Neurol., 12 (2013), pp. 186-194.

[32] S.C. Shin, J.P. Vanderberg, J.A. Terzakis Direct infection of hepatocytes by sporozoites of Plasmodium berghei J Protozool., 29 (1982), pp. 448-454. 
[33] W.Y. Xu, X.X. Wang, J. Qi, J.H. Duan, F.S. Huang Plasmodium yoelii: influence of immune modulators on the development of the liver stage Exp. Parasitol., 126 (2010), pp. 254-258.

[34] M. De Niz, P.C. Burda, G. Kaiser, H.A. Del Portillo, T. Spielmann, F. Frischknecht, V.T. Heussler Progress in imaging methods: insights gained into Plasmodium biology Nat. Rev. Microbiol., 15 (2017), pp. 37-54.

[35] A.F. Cowman, B.S. Crabb Invasion of red blood cells by malaria parasites Cell, 124 (2006), pp. 755-766.

[36]C.V. Greenway, G.E. Lister Capacitance effects and blood reservoir function in the splanchnic vascular bed during non-hypotensive haemorrhage and blood volume expansion in anaesthetized cats J. Physiol., 237 (1974), pp. 279-294.

[37] W.W. Lautt, Hepatic Circulation: Physiology and Pathophysiology, San Rafael (CA), Morgan \& Claypool Life Sciences, Chapter 4 (2009).

[38] G. Biozzi, B. Benacerraf, B.N. Halpern Quantitative study of the granulopectic activity of the reticulo-endothelial system: II: A study of the kinetics of the granulopectic activity of the R.E.S. in Relation to the Dose of Carbon Injected. Relationship between the weight of the organs and their activity Br. J. Exp. Pathol., 34 (1953), pp. 441-457.

[39] B. Benacerraf, M.M. Sebestyen, S. Schlossman A quantitative study of the kinetics of blood clearance of P32-labelled Escherichia coli and Staphylococci by the reticuloendothelial system J. Exp. Med., 110 (1959), pp. 27-48.

[40] K.T. Brunner, D. Hurez, R.T. McCluskey, B. Benacerraf Blood clearance of P32-labeled vesicular stomatitis and Newcastle disease viruses by the reticuloendothelial system in mice J Immunol., 85 (1960), pp. 99-105.

[41] Z. Zeng, B.G. Surewaard, C.H. Wong, J.A. Geoghegan, C.N. Jenne, P. Kubes CRIg functions as a macrophage pattern recognition receptor to directly bind and capture blood-borne gram-positive bacteria Cell Host Microbe, 20 (2016), pp. 99-106.

[42] L.P. Ganesan, S. Mohanty, J. Kim, K.R. Clark, J.M. Robinson, C.L. Anderson Rapid and efficient clearance of blood-borne virus by liver sinusoidal endothelium PLoS Pathog., 7 (2011), p. e1002281.

[43] S.P. Broadley, A. Plaumann, R. Coletti, C. Lehmann, A. Wanisch, A. Seidlmeier, K. Esser, S. Luo, P.C. Rämer, S. Massberg, D.H. Busch, M. van Lookeren Campagne, A. Verschoor Dual-track clearance of circulating bacteria balances rapid restoration of blood sterility with induction of adaptive immunity Cell Host Microbe, 20 (2016), pp. 3648.

[44] J. Tavares, P. Formaglio, S. Thiberge, E. Mordelet, N. Van Rooijen, A. Medvinsky, R. Ménard, R. Amino Role of host cell traversal by the malaria sporozoite during liver infection J. Exp. Med., 210 (2013), pp. 905-915. 
[45] S.J. Cha, M.S. Kim, A. Pandey, M. Jacobs-Lorena Identification of GAPDH on the surface of Plasmodium sporozoites as a new candidate for targeting malaria liver invasion J. Exp. Med., 213 (2016), pp. 2099-2112.

[46] S.J. Cha, K. Park, P. Srinivasan, C.W. Schindler, N. van Rooijen, M. Stins, M. JacobsLorena CD68 acts as a major gateway for malaria sporozoite liver infection J. Exp. Med., 212 (2015), pp. 1391-1403.

[47] S.G. Vreden, R.W. Sauerwein, J.P. Verhave, N. Van Rooijen, J.H. Meuwissen, M.F. Van Den Broek Kupffer cell elimination enhances development of liver schizonts of Plasmodium berghei in rats Infect. Immun., 61 (1993), pp. 1936-1939.

[48] K. Baer, M. Roosevelt, A.B. Jr, N. van Clarkson, T. Rooijen, U. Frevert Schnieder Kupffer cells are obligatory for Plasmodium yoelii sporozoite infection of the Liver Cell. Microbiol., 9 (2007), pp. 397-412.

[49] U. Frevert, S. Engelmann, S. Zougbédé, J. Stange, B. Ng, K. Matuschewski, L. Liebes, H. Yee Intravital observation of Plasmodium berghei sporozoite infection of the liver PLoS Biol., 3 (2005), p. e192.

[50] A.A. Sultan, M.R. Briones, N. Gerwin, M.C. Carroll, V. Nussenzweig Sporozoites of Plasmodium yoelii infect mice with targeted deletions in ICAM-1 and ICAM-2 or complement components C3 and C4 Mol. Biochem. Parasitol., 88 (1997), pp. 263-266.

[51] P. Marshall, A. Rohlmann, V. Nussenzweig, J. Herz, P. Sinnis P, Plasmodium sporozoites invade cells with targeted deletions in the LDL receptor related protein Mol. Biochem. Parasitol., 106 (2000), pp. 293-298.

[52] P. Sinnis, M. Febbraio Plasmodium yoelii sporozoites infect CD36-deficient mice Exp. Parasitol., 100 (2002), pp. 12-16.

[53] M. Cunha-Rodrigues, S. Portugal, M. Febbraio, M.M. Mota Infection by and protective immune responses against Plasmodium berghei ANKA are not affected in macrophage scavenger receptors A deficient mice BMC Microbiol., 6 (2006), p. 73.

[54] S.J. Pancake, G.D. Holt, S. Mellouk, S.L. Hoffman Malaria sporozoites and circumsporozoite proteins bind specifically to sulfated glycoconjugates J. Cell. Biol., 117 (1992), pp. $1351-1357$.

[55] S. Yalaoui, T. Huby, J.F. Franetich, A. Gego, A. Rametti, M. Moreau, X. Collet, A. Siau, G.J. van Gemert, R.W. Sauerwein, A.J. Luty, J.C. Vaillant, L. Hannoun, J. Chapman, D. Mazier, P. Froissard Scavenger receptor BI boosts hepatocyte permissiveness to Plasmodium infection Cell Host Microbe, 4 (2008), pp. 283-292.

[56] C.D. Rodrigues, M. Hannus, M. Prudêncio, C. Martin, L.A. Gonçalves, S. Portugal, S. Epiphanio, A. Akinc, P. Hadwiger, K. Jahn-Hofmann, I. Röhl, G.J. van Gemert, J.F. Franetich, A.J. Luty, R. Sauerwein, D. Mazier, V. Koteliansky, H.P. Vornlocher, C.J. Echeverri, M.M. Mota Host scavenger receptor SR-BI plays a dual role in the establishment of malaria parasite liver infection Cell Host Microbe, 4 (2008), pp. 271-282. 
[57] L. Foquet, C.C. Hermsen, L. Verhoye, G.J. van Gemert, R. Cortese, A. Nicosia, R.W. Sauerwein, G. Leroux-Roels, P. Meuleman Anti-CD81 but not anti-SR-BI blocks Plasmodium falciparum liver infection in a humanized mouse model J. Antimicrob. Chemother., 70 (2015), pp. 1784-1787.

[58] L. Song, C. Lee, C. Schindler Deletion of the murine scavenger receptor CD68 J. Lipid Res., 52 (2011), pp. 1542-1550.

[59] J.E. Puche, Y.A. Lee, J. Jiao, C. Aloman, M.I. Fiel, U. Muñoz, T. Kraus, T. Lee, H.F. Yee Jr., S.L. Friedman A novel murine model to deplete hepatic stellate cells uncovers their role in amplifying liver damage in mice Hepatology, 57 (2013), pp. 339-350.

[60] O. Silvie, E. Rubinstein, J.F. Franetich, M. Prenant, E. Belnoue, L. Rénia, L. Hannoun, W. Eling, S. Levy, C. Boucheix, D. Mazier Hepatocyte CD81 is required for Plasmodium falciparum and Plasmodium yoelii sporozoite infectivity Nat. Med., 9 (2003), pp. 93-96.

[61] A. Kaushansky, A.N. Douglass, N. Arang, V. Vigdorovich, N. Dambrauskas, H.S. Kain, L.S. Austin, D.N. Sather, S.H. Kappe Malaria parasites target the hepatocyte receptor EphA2 for successful host infection Science, 350 (2015), pp. 1089-1092.

\section{TABLES \& FIGURES}

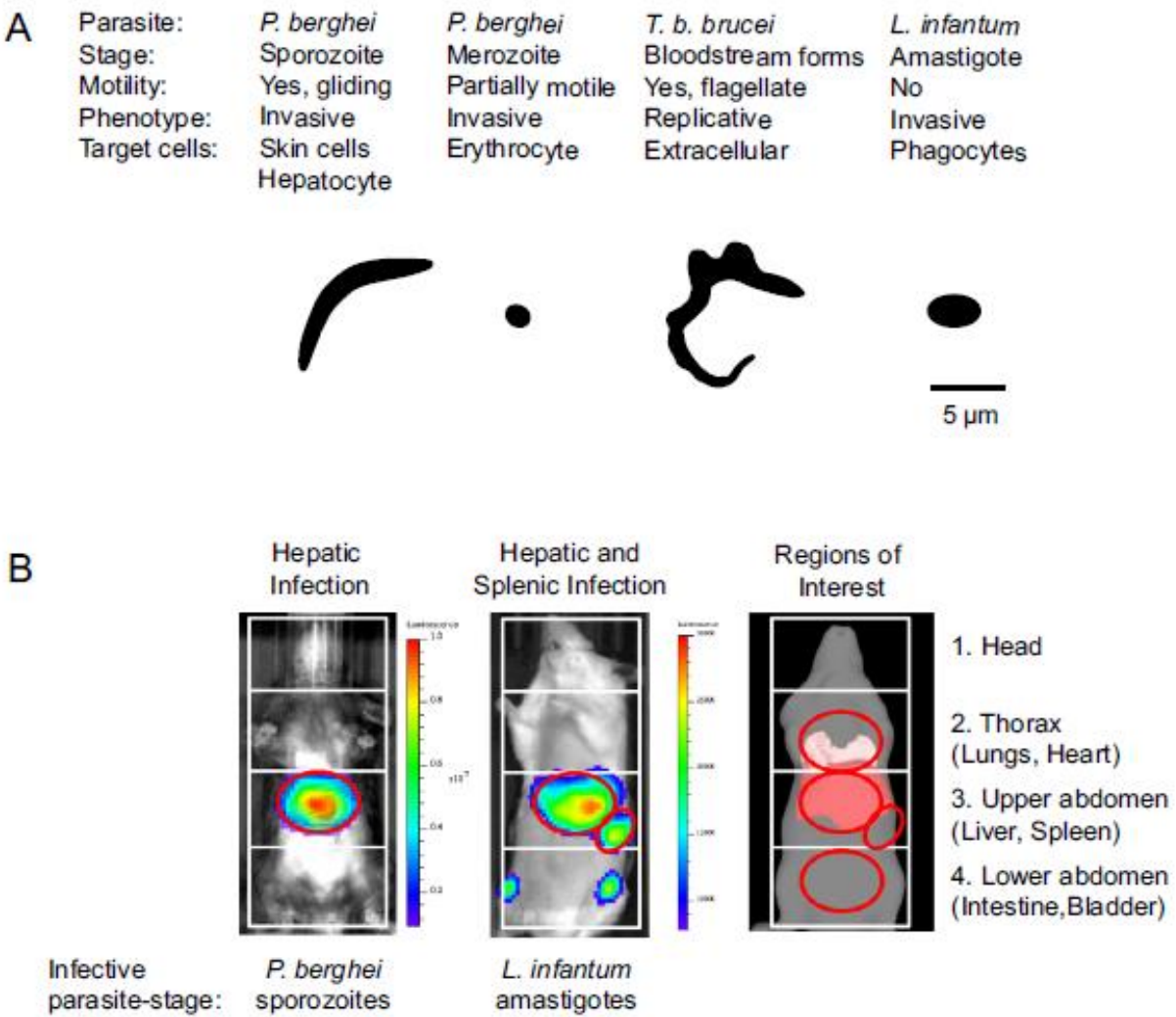

Figure 1. Defining pathogens and regions of interest in the host. (A) Schematic representation of parasite species and stages used in this work to evaluate by ventral body in vivo bioluminescence imaging the parasite homing and infectivity to the host organs. (B) Defining the Regions of Interest (ROls) used for quantitative analysis. The ventral view of the animal body was divided into four main rectangular regions to delineate the head, thorax, upper abdomen and lower abdomen. Inside these regions and for quantification purposes elliptical ROls were drawn with Living Image software. The liver and spleen ROls in the upper abdomen were defined based on the bioluminescence signal of mice infected with $P$. berghei sporozoites (day 2; left) and $L$. infantum amastigotes (day 2; middle). The schematic mice model (right) was obtained from the IVIS digital atlas. 

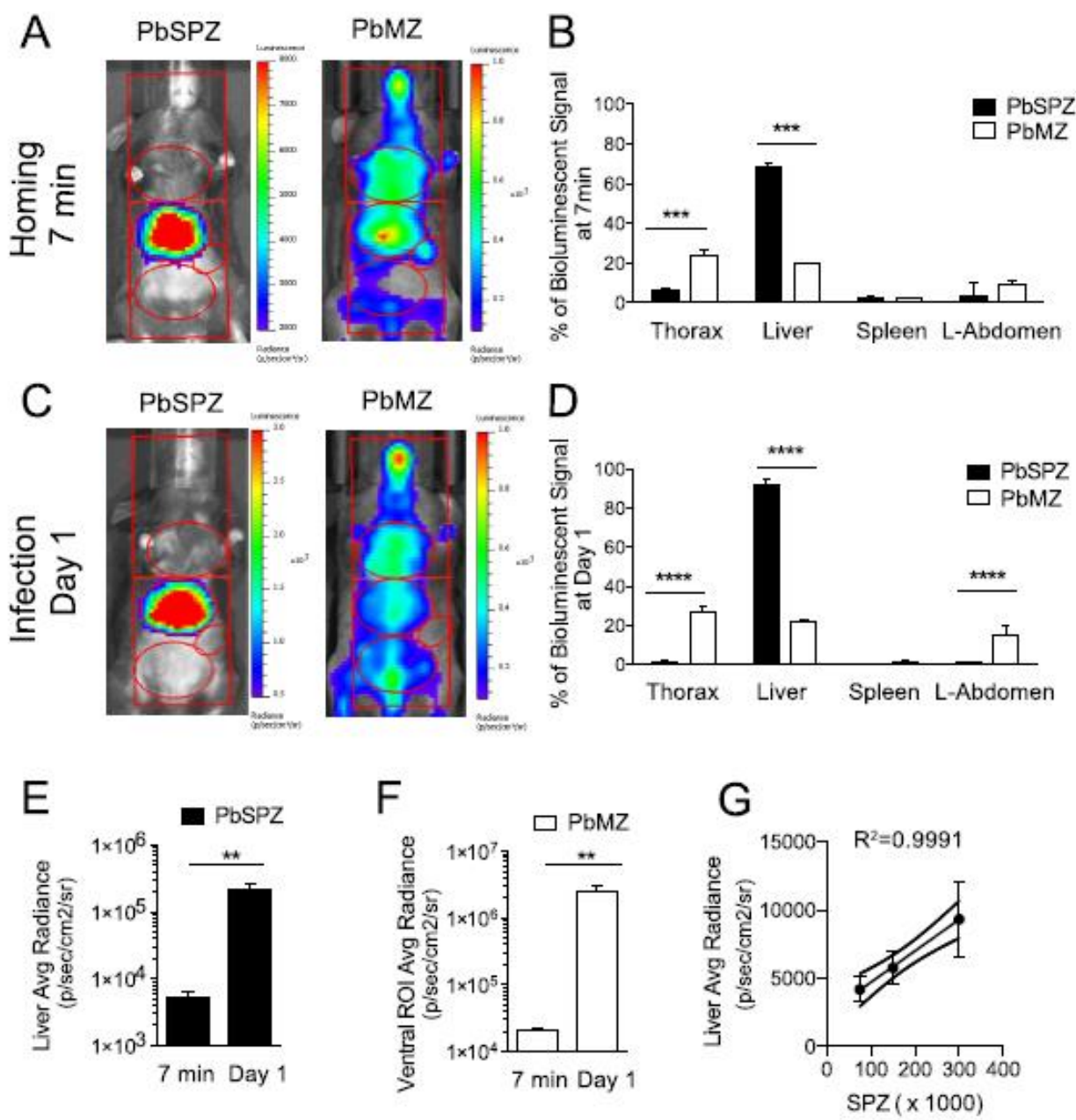

Figure 2. $P$. berghei salivary gland sporozoites home to the liver immediately after intravascular inoculation. C57BL/6 mice were injected intravenously with luciferase expressing salivary gland sporozoites (PbSPZ) or blood merozoites (PbMZ), and the distribution of parasites was evaluated by bioluminescence imaging at 7 min (A-B) and day 1 (C-D). $(B ; D)$ The percentage of the bioluminescence signal in the thorax, liver, spleen and lower-abdomen was calculated dividing the total flux (photons/s) of the respective ROls by that of the ventral ROI previously subtracted by the background values calculated from non-infected mice. The graphs show the mean + standard deviation $(n=3)$ and are representative of at least 2 independent experiments. Statistical significance between sporozoites and merozoites was determined using 2-way ANOVA with Sidak's multiple comparisons test. (E) Quantification at 7 min and day 1 of liver infection in average radiance (photons $/ \mathrm{s} / \mathrm{cm}^{2} /$ steradian) following sporozoite injection. (F) Quantification at $7 \mathrm{~min}$ and day 1 of whole body infection in average radiance (photons $/ \mathrm{s} / \mathrm{cm}^{2} /$ steradian) following merozoite injection. (E-F) Statistical significance calculated by Students $t$-test. " $p<0.01 ;{ }^{* * *} p<0.001 ;{ }^{* * * *} p<0.0001$. (G) Quantification of the liver average radiance (photons $/ \mathrm{s} / \mathrm{cm}^{2} /$ steradian) at $7 \mathrm{~min}$ following intravenous injection of different numbers of sporozoites. The graph shows the linear regression of the bioluminescent signal with the $95 \%$ confidence bands $\left(R^{2}=0.99\right)$ Symbols represent mean \pm standard deviation $(n=3)$.

INSTITUTO DE INVESTIIGAÇÃO E INOVAÇÃO EM SAÚDE UNIVERSIDADE DO PORTO

Rua Alfredo Allen, 208 4200-135 Porto Portugal $+351220408800$ 
A
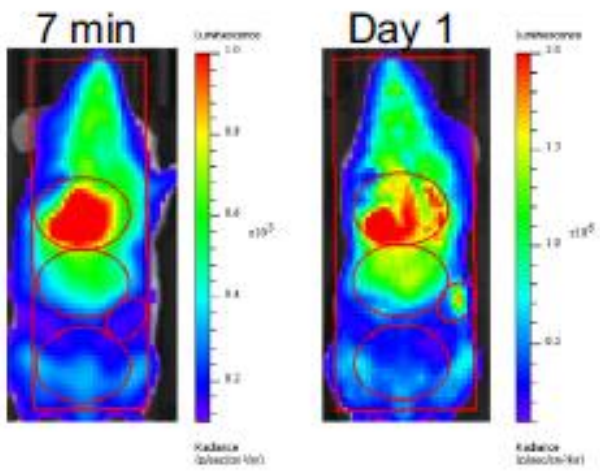

B
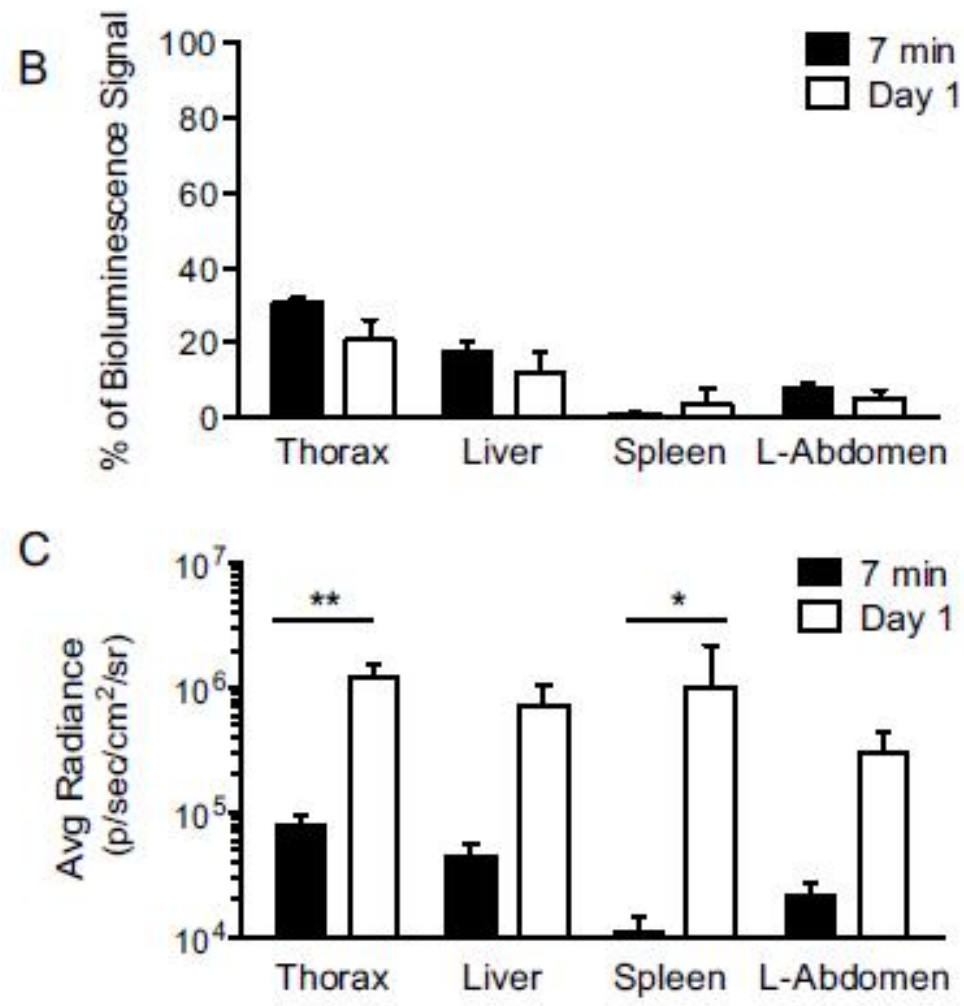

Figure 3. Relative distribution and replication of T. b. brucei bloodstream forms. (A-C) BALB/c mice were injected intravenously with red-shifted luciferase expressing Tb bloodstream forms and the distribution of parasites evaluated by bioluminescence imaging at $7 \mathrm{~min}$ and day 1 . (B) The percentage of the bioluminescence signal in the thorax, liver, spleen and lower-abdomen was calculated dividing the total flux (photons/s) of the respective ROls by that of the ventral ROI previously subtracted by the background values calculated from non-infected mice. (C) Quantification of the bioluminescence signal in average radiance (photons $/ \mathrm{s} / \mathrm{cm}^{2} / \mathrm{steradian}$ ) in the thorax, liver, spleen and lower abdomen. (B-C) The graphs show the mean + standard deviation $(n=4)$ and are representative of 2 independent experiments. Statistical significance between $7 \mathrm{~min}$ and day 1 for the several regions of interest was determined using 2-way ANOVA with Sidak's multiple comparisons test. $p<0.05 ; " p<0.01$. 
A
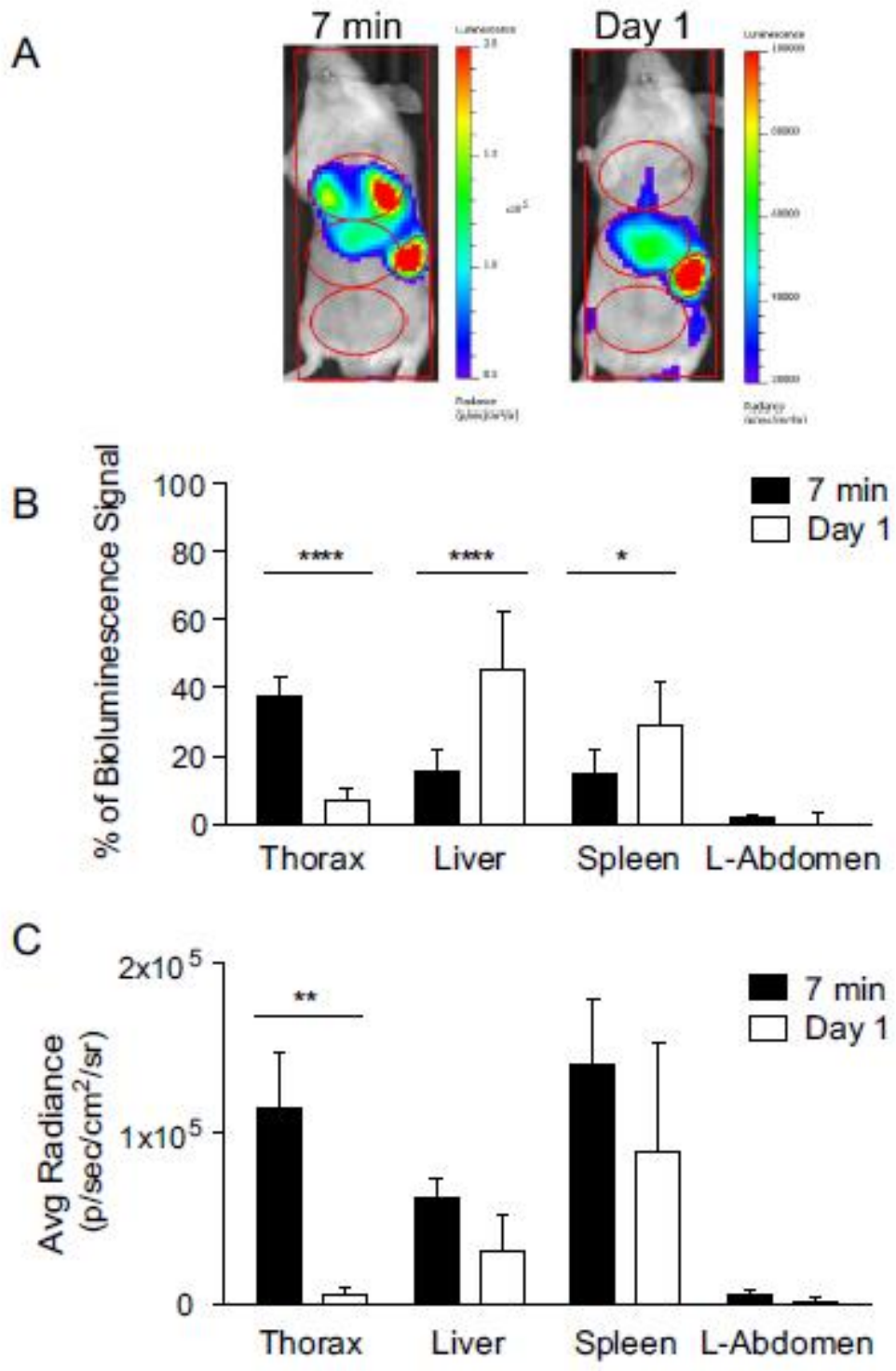

Figure 4. Homing and infection of $L$. infantum amastigotes. (A-C) BALB/c mice were injected intravenously with luciferase expressing axenic $\mathrm{Li}$ amastigotes and the distribution of parasites evaluated by bioluminescence imaging at $7 \mathrm{~min}$ and at day 1. (B) The percentage of the bioluminescence signal in the thorax, liver, spleen and lowerabdomen was calculated dividing the total flux (photons/s) of the respective ROls by that of the ventral ROI previously subtracted by the background values calculated from non-infected mice. (C) Quantification of the bioluminescence signal in average radiance (photons $/ \mathrm{s} / \mathrm{cm}^{2} /$ steradian) in the thorax, liver, spleen and lower abdomen. (B-C) The graphs show the mean + standard deviation $(n=3)$ and are representative of 2 independent experiments. Statistical significance between $7 \mathrm{~min}$ and day 1 for the several regions of interest was determined using 2-way ANOVA with Sidak's multiple comparisons test. $p<0.05 ; " p<0.01 ; \quad p<0.0001$. 

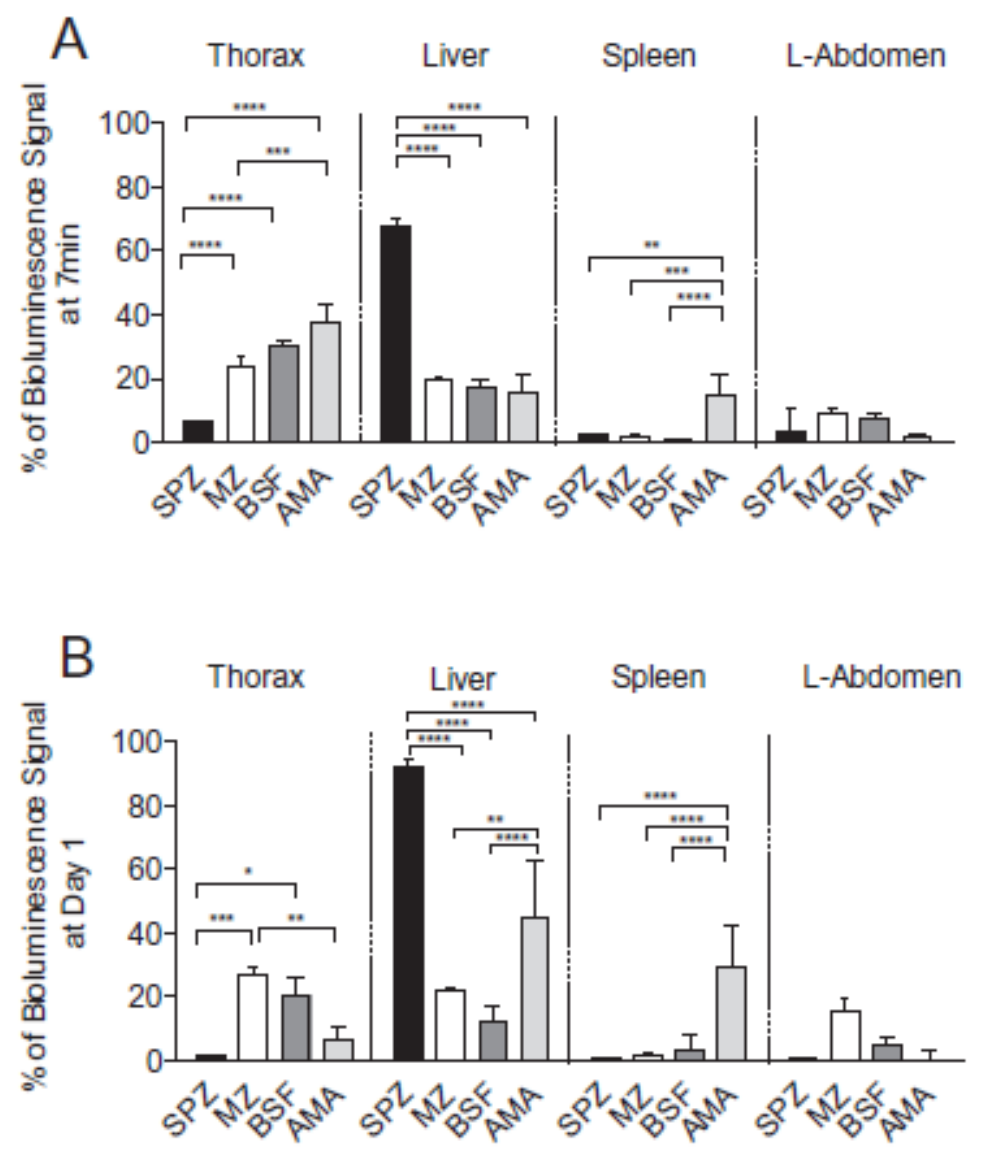

Figure 5. Summary of homing and infection of parasites. Comparative analysis of the distribution of the bioluminescence signal (\%) in the first minutes $(A)$ and at day 1 (B) following intravenous injection of $P$. berghei sporozoites (SPZ) or merozoites (MZ), T. b. brucei bloodstream forms (BSF) or L. infantum amastigotes (AMA). (A-B) The graphs show the mean + standard deviation $(n=3-4)$ and are representative of at least 2 independent experiments. Statistical significance between the different parasite stages was evaluated using 2-way ANOVA with Sidak's multiple comparisons test. $p<0.05 ;{ }^{* *} p<0.01 ;{ }^{* * *} p<0.001 ;{ }^{* * * *} p<0.0001$. 